Marquette University

e-Publications@Marquette

College of Education Faculty Research and

Publications

Education, College of

10-1997

\title{
Sexual Attraction Toward Clients, Use of Supervision, and Prior Training: A Qualitative Study of Predoctoral Psychology Interns
}

\author{
Nicholas Ladany \\ Lehigh University \\ Karen M. O'Brien \\ University of Maryland - College Park \\ Clara E. Hill \\ University of Maryland - College Park \\ Deborah S. Melincoff \\ Lehigh University \\ Sarah Knox \\ Marquette University, sarah.knox@marquette.edu
}

See next page for additional authors

Follow this and additional works at: https://epublications.marquette.edu/edu_fac

Part of the Education Commons

\section{Recommended Citation}

Ladany, Nicholas; O'Brien, Karen M.; Hill, Clara E.; Melincoff, Deborah S.; Knox, Sarah; and Peterson, David A., "Sexual Attraction Toward Clients, Use of Supervision, and Prior Training: A Qualitative Study of Predoctoral Psychology Interns" (1997). College of Education Faculty Research and Publications. 454.

https://epublications.marquette.edu/edu_fac/454 
Authors

Nicholas Ladany, Karen M. O'Brien, Clara E. Hill, Deborah S. Melincoff, Sarah Knox, and David A. Peterson

This article is available at e-Publications@Marquette: https://epublications.marquette.edu/edu_fac/454 
Marquette University

\section{e-Publications@Marquette}

\section{Education Faculty Research and Publications/College of Education}

This paper is NOT THE PUBLISHED VERSION; but the author's final, peer-reviewed manuscript. The published version may be accessed by following the link in th citation below.

Journal of Counseling Psychology, Vol. 44, No. 4 (1997): 413-424. DOI. This article is (C) American Psychological Association and permission has been granted for this version to appear in $\underline{\mathrm{e}}-$ Publications@Marquette. American Psychological Association does not grant permission for this article to be further copied/distributed or hosted elsewhere without the express permission from American Psychological Association.

\section{Sexual Attraction Toward Clients, Use of Supervision, and Prior Training: A Qualitative Study of Predoctoral Psychology Interns}

Nicholas Ladany

Department of Education and Human Services, Lehigh University;

Karen M. O'Brien

Department of Psychology, University of Maryland College Park

Clara E. Hill

Department of Psychology, University of Maryland College Park

Deborah S. Melincoff

Department of Education and Human Services, Lehigh University

Sarah Knox

Marquette University, Milwaukee, WI

Department of Psychology, University of Maryland College Park 
David A. Petersen

Department of Psychology, University of Maryland College Park

\section{Acknowledgement}

Earlier versions of this article were presented at the annual meeting of the Society for Psychotherapy Research, Amelia Island, Florida, June 1996, and at the 104th Annual Convention of the American Psychological Association, Toronto, Ontario, Canada, August 1996. We are grateful to Robert A. Brown, Leslie K. Orysh, and Kenneth S. Pope for their comments on an earlier version of this article. We also thank Linda Tipton for her assistance with the data coding and Michelle Bosio, Shawn Eigenbrode, Michele Forstot, Jennifer Hudson, Gopa Kahn, Elisaida Mendez, Susan Reynolds, Sharon Weiss Cohen, and Jamell White for their assistance with transcribing the interviews.

\section{Note}

Charles D. Claiborn served as the action editor for this article.-CEH

\section{Abstract}

Interviews were conducted with 13 predoctoral psychology interns about an experience of sexual attraction toward a client, use of supervision to address the sexual attraction, and prior training regarding sexual attraction. Results indicated that sexual attraction to clients consisted of physical and interpersonal aspects. Therapists believed they were more invested and attentive than usual to clients to whom they were sexually attracted, and they indicated that sexual attraction created distance, distraction, and loss of objectivity. In terms of supervision, only half of the participants disclosed their sexual attraction to supervisors, and supervisors seldom initiated the discussion. Furthermore, trainees found it helpful when supervisors normalized the sexual attraction and provided the opportunity to explore feelings in supervision. Finally, trainees believed their training programs did not adequately address therapist sexual attraction.

\section{Keywords}

use of prior training and supervision to address sexual attraction toward clients, 27-39 yr old predoctoral psychology interns, conference presentation

\section{Introduction}

Historically, sexual attraction toward clients has been considered an aspect of countertransference (i.e., a reaction to the client's transference; Freud, 1915/1983) or to stem from a problem with the therapist (Kaplan, 1977). Recently, therapists' sexual feelings toward clients have been recognized as a common, although complicated, dynamic involving both realistic and unrealistic reactions that most therapists experience at some point in their professional lives (Gabbard, 1994, 1995; Pope, Keith-Spiegel, \& Tabachnick, 1986). In fact, research has indicated that more than $84 \%$ of therapists become sexually attracted to a client at some point during their practice of psychotherapy (Pope et al., 1986; Rodolfa et al., 1994). The purpose of our study was to examine the process of therapists' sexual attraction toward clients, the manner in which therapists are able to use supervision to assist them in managing and resolving their feelings of sexual attraction, and the training they receive regarding such feelings. 
To date, participants in studies on therapist sexual attraction have been psychologists in private practice (Pope et al., 1986) and in university counseling centers (Rodolfa et al., 1994) and social workers (Bernsen, Tabachnick, \& Pope, 1994). A summary of the results of these survey investigations (combined sample sizes exceeding 385) indicated that most therapists have been sexually attracted to at least one client, with male therapists consistently reporting greater sexual attraction than female therapists. Although therapists rarely considered sexual involvement, they occasionally had sexual fantasies about the client. Also, therapists were sexually attracted to physical and psychological characteristics of their clients, and they often experienced discomfort, guilt, or anxiety as a result of having the sexual attraction. Many therapists also perceived the sexual attraction to be, more often than not, beneficial to the therapy process (with nearly half also noting negative effects). Furthermore, many therapists believed the client was not aware of the therapist's sexual attraction, but most believed that the sexual attraction was reciprocal. In terms of supervision and training, more than half of the therapists sought supervision or consultation at least once, which they believed would involve a positive supervisory or collegial relationship; during their training programs or internships, about half of the therapists had received no, or at best poor, education about issues of sexual attraction.

The consistency of findings across these studies is impressive. These studies indicate reliable trends and thus strengthen our understanding of sexual attraction to clients. However, the generalization of the results to specific client-counselor interactions is limited because of the manner in which the information was elicited. Using a survey methodology, the authors of the aforementioned studies assessed the sexual attraction process for all clients to whom a therapist had been sexually attracted instead of for a specific client-counselor interaction. Furthermore, the surveys contained predominantly structured, closed-ended questions that failed to capture the inner experiences of trainees. Thus, a more in-depth qualitative analysis of specific instances of therapists' experiences of sexual attraction seemed warranted, and this was the first purpose of our investigation. By examining specific instances in which trainees felt sexually attracted to clients, we hoped to learn more about what may have caused them to feel this sexual attraction and how they managed these feelings.

One aspect of the therapist sexual attraction process that has received limited attention is therapists' use of supervision when sexually attracted to clients. Pope, Sonne, and Holroyd (1993) have suggested that by disclosing in supervision feelings of sexual attraction to clients, therapists can be assisted in working through their sexual feelings in a healthy, rather than a destructive, manner. Rodolfa et al. (1994) found that $60 \%$ of their sample of postdoctoral psychologists sought supervision or consultation to examine their feelings of sexual attraction. Those who did not seek supervision reported that the sexual attraction was not interfering with therapy or that they feared a negative reaction from a supervisor. Similarly, Stake and Oliver (1991) found that about $50 \%$ of their sample of psychologists discussed with a supervisor their sexual attraction toward a client, and $19 \%$ discussed these issues with a therapist.

Whereas most of the research to date has assessed the attitudes and behaviors of practicing psychotherapists, none has specifically examined psychology trainees, who are in a prime position to benefit from supervisory interventions. Unique to trainees is their involuntary involvement in individual psychotherapy supervision (Bernard \& Goodyear, 1992; Blocher, 1983), which ostensibly provides them with the opportunity to discuss, work through, and prevent potentially damaging consequences of their sexual attraction toward clients (Ellis \& Douce, 1994; Pope et al., 1993). However, in a related study on trainees' nondisclosure, Ladany, Hill, Corbett, and Nutt (1996) found that trainees did not disclose many things to their supervisors, including their sexual attraction toward their clients. Moreover, a primary reason for the nondisclosure to their supervisors was that these predoctoral trainees felt their sexual attraction to clients was unimportant (Ladany et al., 1996). Hence, it is unclear whether trainees, even though they are in a position to benefit from supervision, actually use supervision to help them with sexual feelings toward clients. Thus, our second purpose was to examine the extent to which supervision was used when therapists-in-training were sexually attracted to a client. 
Training programs in which therapists learn about sexual attraction to clients have been noted as another relevant research area (Rodolfa et al., 1994; Vasquez, 1988; Yarris \& Allgeier, 1988). No training-or poor training -in sexual attraction issues has been reported by more than half of surveyed psychologists (Pope et al., 1986; Pope \& Tabachnick, 1993; Rodolfa et al., 1994), marriage and family therapists (Nickell, Hecker, Ray, \& Bercik, 1995), and social workers (Bernsen et al., 1994). Although training was generally described as inadequate, the specifics of therapists' dissatisfaction are unclear. Hence, our third purpose was to determine the helpful and unhelpful aspects of training in graduate programs and internships regarding sexual attraction issues.

In sum, the first purpose of our study was to describe the experience of therapists' sexual attraction toward clients, particularly the thoughts and feelings associated with the sexual attraction, how the sexual attraction developed, client and therapist factors associated with the sexual attraction, the impact of sexual attraction on therapy, dreams and fantasies associated with the sexual attraction, and how the sexual attraction was managed and resolved. Our second purpose was to explore how therapists used supervision to address their sexual attraction-specifically, whether therapists disclosed their sexual attraction in supervision, supervisors' reactions to disclosures or supervisory factors associated with nondisclosures, and the manner in which the supervisory relationship influenced their disclosures or nondisclosures. We studied therapists who were in their predoctoral internships because we assumed that they would have a greater understanding than novices would of the therapy process and, unlike postdoctoral therapists, would be in a unique position to use supervision. Our third purpose was to examine the extent to which therapists were trained during their graduate programs and internships to manage and examine their sexual attraction toward clients. Finally, we used a consensual qualitative research ( $\mathrm{Hill}$, Thompson, \& Williams, in press) approach because we wanted to obtain an indepth understanding of therapists' experiences of sexual attraction to clients.

\section{Method}

\section{Participants}

Thirteen psychology interns ( 10 White, 2 Latina, and 1 Middle Eastern; 8 women, 5 men; 11 heterosexuals, 1 gay man, 1 lesbian) who ranged in age from 27 to 39 years $(M=31.23, S D=4.15)$ participated in this study. Participants were from doctoral programs in either counseling $(n=9)$ or clinical $(n=4)$ psychology. On average, interns had 45.23 months ( $M d n=48.00, S D=15.42$ ) of counseling experience since entering their doctoral programs. Twelve of the 13 interns had been in therapy themselves $(M=27.50$ months, $M d n=9.00, S D=35.62)$. Participants noted that in general, they were sometimes $(n=6)$ or rarely $(n=7)$ sexually attracted to clients. None of the participants reported any sexual activity with the clients to whom they were sexually attracted.

The therapists reported being sexually attracted to eight male clients (seven clients were White and one was Latino; seven were heterosexual and one was bisexual) and five female clients (four clients were White and one was Latina; all were heterosexual). Eleven cases involved heterosexual attraction and two cases involved gay male or lesbian attraction. The clients' presenting problems had to do with issues of relationship-trust (nine cases), drugs and alcohol (four cases), individuation-self-esteem (four cases), family of origin (two cases), anger management (one case), depression (one case), sex addiction (one case), and lack of direction (one case). At the time of the sexual attraction, participants were supervised by 3 White male and 10 White female supervisors ( 9 PhD psychologists, 1 PsyD psychologist, 1 EdD psychologist, 1 psychiatrist, and 1 licensed clinical social worker).

\section{Researchers}

The primary researchers for this study were three White doctoral-level counseling psychologists (Nicholas Ladany Karen O'Brien and Clara E. Hill); three White graduate students (Deborah S. Melincoff, Sarah Knox, and 
David A. Petersen) in doctoral programs in counseling psychology served as the interviewers. All six served as judges for the coding tasks.

Prior to collecting data, we noted our biases and expectations regarding the potential findings of the study. We discussed these biases and expectations to increase awareness and to minimize their impact on the data analysis. Four of us believed that most trainees would admit that they had been sexually attracted to a client, and that shame, guilt, and embarrassment would accompany the sexual attraction. One of us expected that the sexual attraction would not be extremely intense. Three believed that the guilt and shame might inhibit disclosure of the sexual attraction to the participant's supervisor. Four of us agreed that the trainee would be more likely to disclose to a supervisor if the supervisor was supportive, open, and caring and if there was a strong working alliance between them. One of us suspected that most of the trainees would disclose the sexual attraction to their supervisors, whereas another expected that the supervisor would need to broach the topic if it was to be discussed at all. Two of us believed that the participants would have received less than adequate training in this area. In sum, we were quite interested in the topic and reported some range of expectations about it. None of us reported particularly traumatic experiences having to do with sexual attraction to clients, and all of us indicated an openness to discovering what was to be found in the data.

\section{Measure}

After reviewing the literature on sexual attraction in therapy (e.g., Pope, 1990; Pope et al., 1986), we composed a semistructured interview. In the final version of the interview, questions were openended, as suggested by McCracken (1988), to ensure that participants would have the freedom to answer in an unstructured fashion. The interview questions were divided into 10 areas: (a) discussion of the client to whom the intern was sexually attracted (description of the sexual attraction, client's awareness of the sexual attraction, the client's attractive qualities, whether the client reciprocated the sexual attraction, demographic questions about the client), (b) the course of the sexual attraction (what led to the intern's awareness of the sexual attraction, thoughts and feelings about the sexual attraction, dreams and fantasies related to the sexual attraction), (c) the influence of the sexual attraction on the counseling relationship (influence on outcome of therapy, personal factors that may have been related to the sexual attraction, management and resolution of the sexual attraction), (d) the discussion of the sexual attraction in supervision (whether the intern disclosed sexual attraction to supervisor, what was helpful or not helpful, the relationship with the supervisor, the ways in which the sexual attraction affected the supervisory relationship), (e) the extent to which the interns' training programs dealt with the issue of sexual attraction, (f) how they were trained to deal with sexual attraction issues, (g) the ways in which internships dealt with sexual attraction issues, (h) thoughts about how training programs and internships should deal with the issue of sexual attraction, (i) biographical information about the participants, and (j) biographical questions about supervisors. Interviewers were encouraged to probe the participants' answers to clarify any issues. We conducted pilot interviews with three advanced graduate students in psychology, and we used their suggestions to revise the interview.

\section{Procedure}

We used a qualitative methodology to answer the research questions of this investigation. Specifically, we followed the procedures suggested by $\mathrm{Hill}$ et al. (in press) for consensual qualitative research, which are detailed below. 


\section{Recruiting}

We gave a total of 77 packets to colleagues at 18 college counseling centers nationally, who agreed to distribute these packets to their intern trainees or fellow interns who might consider participating in the study. The contacts were not aware of whether or not the interns chose to participate. Once the potential participants opened the materials, they were asked in a cover letter if they would participate in a study regarding sexual attraction to clients. Specifically, we mentioned that as part of the study, we were going to have them reflect on their experiences doing therapy over the past 2 years and describe the client to whom they were most sexually attracted. We also noted in the cover letter that we believed sexual attraction toward clients to be a normal part of the therapy process. We informed potential participants that they would need to be available for two phone interviews over the span of 2 weeks. We then asked them to complete a questionnaire containing demographic questions, an item asking if they had been sexually attracted to a client, and, if they wished to participate, a first name, phone number, and time when they could be reached. A list of the interview questions was enclosed so that participants could review the questions prior to the interview. We informed potential participants that they would be given Pope et al.'s (1993) book in appreciation for their participation. Questionnaires were returned in self-addressed, stamped envelopes.

Of the 77 interns sampled, 22 responded. Seven people declined to participate, 1 person participated but reported he had not experienced sexual attraction to a client, and 1 person could not be reached by phone. The 8 nonparticipants did not differ from the 13 participants in terms of gender, race, or age, but the nonparticipants reported that they had never been sexually attracted to a client.

\section{Interviews}

We randomly assigned participants to interviewers. The assigned interviewer called the participant to arrange a time for the interview. Only the first name of the participant was used to set up and conduct the interviews. We informed participants that the interview would be taped and that their responses would be kept anonymous. At the end of the first 30-45 min interview, the interviewer and participant set up a time for a 10-15 min follow-up interview. During the time between the two interviews, another researcher on the team listened to the initial interview and gave suggestions for further probing during the follow-up interview. Also, the follow-up interview gave interviewers a chance to think of areas to probe further and provided participants with an opportunity to reflect on the initial interview and provide additional information. After the follow-up interview, interviewers asked participants to send their names and addresses on a postcard to one of the graduate students on the research team so that the participants could receive the book that served as the research incentive. Thus, there was no way to link the name of the intern to a specific interview. Following the interviews, we assigned each participant a code number, which was subsequently used to ensure anonymity.

\section{Data preparation}

Research assistants transcribed the audiotapes verbatim (except for minimal phrases such as "um hmm"), omitting any identifying information about the participant. A different research assistant than the original transcriber checked these transcripts against the audiotape for accuracy. The original interviewer then again checked the transcripts against the audiotape for accuracy.

\section{Coding into domains}

After developing an initial "start list" of domains (topic areas) based on the interview questions, the six of us independently reviewed three transcribed interviews to categorize all material in a transcript that related to the same idea into domains and then argued to consensus about the best assignment. For example, we coded in the emergence-of-sexual-attraction domain information related to the point in therapy when the sexual attraction was noticed by the therapist. We modified the domains to fit the data during the coding process, resulting in the following final list of 19 domains: (a) emergence of sexual attraction, (b) therapist experience of sexual attraction, (c) client factors associated with therapist sexual attraction, (d) client awareness of therapist sexual 
attraction, (e) client reciprocation of sexual attraction, $(f)$ influence of sexual attraction on therapy process, $(g)$ influence on termination, (h) influence on outcome, (i) dreams and fantasies about client, (j) sexual activity with client, $(\mathrm{k})$ management of sexual attraction, $(\mathrm{I})$ resolution of sexual attraction, $(\mathrm{m})$ therapist factors concurrent with sexual attraction, $(\mathrm{n})$ disclosed to supervisor, (o) not disclosed to supervisor, $(\mathrm{p})$ how training program dealt with sexual attraction issues, (q) how internship dealt with sexual attraction issues, $(r)$ suggestions for training programs and internships, and (s) other thoughts and reactions. Rotating teams of two judges completed the domain coding for the remaining transcripts (i.e., judges independently assigned domains and then the two judges discussed each categorization and came to consensus).

\section{Abstracting core ideas within domains}

Rotating teams of three judges independently read the raw data within each domain and formulated core ideas (i.e., summary statements). The purpose of creating core ideas was to capture the content of all the interview data in the domain in a succinct manner. For example, when questioned about what a participant was trained to do if feelings of sexual attraction occurred, the participant responded, "Uh . . . consult. Talk to a supervisor or if you're not being supervised, then talk to a peer." The abstracted core idea was "intern was trained to consult with supervisors or peers." Next, the team of three judges discussed their core ideas until they reached consensus about the wording of each core idea. We developed a consensus version for each case that consisted of these core ideas and the corresponding interview data for each domain.

\section{Auditing of core ideas}

After the consensus version was completed, two other persons from the larger team audited the consensus version to check if the raw data were appropriately coded into the domains, as well as to check the accuracy and wording of the core ideas. The auditors gave their written feedback individually to the primary team, who discussed the feedback and agreed on any changes made to the consensus version.

\section{Cross-analysis}

The purpose of the cross-analysis was to identify patterns of responses across participants within specific domains. We divided into rotating teams of three to examine the data within each domain. These teams developed categories by looking for similarities in the core ideas for each domain across the 13 cases. For example, we divided the data in the resolution-of-sexual-attraction domain into two categories: "completely resolved" (5 cases) and "not completely resolved" (8 cases).

Once the categories had been created, the team reexamined the abstracted core ideas and the raw data within each domain for each participant to determine whether information relevant to each of the categories had been coded adequately. If additional information was found, the team determined by consensus whether or not to add the information to the core ideas and the appropriate category in the cross-analysis.

\section{Auditing of cross-analyses}

The three people who were not involved in developing the categories for a domain in the crossanalysis served as auditors for that domain. These auditors reviewed the cross-analysis to make sure that the data had been captured adequately. The initial team discussed and agreed on any necessary changes.

\section{Review by entire team}

The entire team discussed the results to ensure that there was consensus. 


\section{Results}

Tables 1 and 2 show the number of cases fitting into each of the categories and subcategories within the domains. Using criteria suggested by Hill et al. (in press), we described a category as general if it applied to all 13 cases, typical if it applied to 7-12 cases, and variant (occasional, in a few cases) if it applied to 3-6 cases. We dropped categories that applied to only 1-2 cases. (The actual differences between general and typical categories, or between typical and variant categories, were minimal in some instances and hence should be treated cautiously.)

Table 1. Number of Cases for Categories From the Cross-Analysis of the 13 Cases of Sexual Attraction and Related Factors

\begin{tabular}{|l|l|}
\hline Domain and category & No. of cases \\
\hline Emergence of sexual attraction & \\
\hline Sexual attraction emerged after therapy began & 8 \\
\hline Sexual attraction at first sight & 5 \\
\hline Therapist experience of sexual attraction & \\
\hline Negative feelings & 10 \\
\hline Physical response evoked in therapist & 7 \\
\hline Positive feelings & 5 \\
\hline Client factors associated with therapist sexual attraction & \\
\hline Client was physically attractive & 10 \\
\hline Client was interpersonally attractive & 12 \\
\hline Client was a good therapy client & 8 \\
\hline Client seemed needy or vulnerable & 5 \\
\hline Client was sexually provocative or flirtatious & 4 \\
\hline Client had attractive personality & 4 \\
\hline Client was similar to therapist & 6 \\
\hline Client was similar to therapist's previous or current romantic partner| & 4 \\
\hline Client was not usual type therapist finds attractive & 3 \\
\hline Client awareness of therapist sexual attraction & \\
\hline No indication client aware of therapist's sexual attraction & 12 \\
\hline Client reciprocation of sexual attraction & \\
\hline No indication client sexually attracted to therapist & 6 \\
\hline Therapist uncertain if client sexually attracted to therapist & 4 \\
\hline Client sexually attracted to therapist & 3 \\
\hline Influence of sexual attraction on therapy process & 10 \\
\hline More investment, caring, attention & 7 \\
\hline Created tension or distance & 6 \\
\hline Too giving/lost boundaries & 4 \\
\hline Intrusive/distracting & 4 \\
\hline Less objectivity & 8 \\
\hline Influence on termination ${ }^{a}$ & \\
\hline Difficulty with termination & \\
\hline Perceived no effect on termination & \\
\hline Influence on outcome & \\
\hline No effect or uncertain effect & \\
\hline Dreams and fantasies about client & \\
\hline Dreams & \\
\hline & \\
\hline
\end{tabular}




\begin{tabular}{|l|l|}
\hline None reported & 8 \\
\hline Reported dreams of possible sexual nature & 5 \\
\hline Dreams alerted therapist to, or intensified, sexual attraction & 3 \\
\hline Fantasies & \\
\hline None reported & 8 \\
\hline Reported fantasies of possible sexual nature & 5 \\
\hline Management of sexual attraction & \\
\hline Thought/reflected/worked through sexual attraction feelings on own & 7 \\
\hline Discussed with supervisor & 6 \\
\hline More attentive or cautious with case than usual & 4 \\
\hline Discussed with someone other than supervisor & 4 \\
\hline Denied, refocused, or repressed feelings or thoughts & 4 \\
\hline Resolution of sexual attraction & \\
\hline Not completely resolved & 8 \\
\hline Completely resolved & 5 \\
\hline Therapist factors concurrent with sexual attraction & \\
\hline Relationship status & \\
\hline In problematic romantic relationship & 5 \\
\hline In relatively good romantic relationship & 5 \\
\hline Not currently in romantic relationship & 3 \\
\hline Concurrent stressors & 5 \\
\hline How training program dealt with sexual attraction issues & \\
\hline Sexual attraction not addressed adequately & 9 \\
\hline Instructed to talk to their supervisors, consult, or seek own therapy & 8 \\
\hline Addressed in ethics class & 7 \\
\hline Environment not open to, or safe for, discussing sexual attraction & 5 \\
\hline Understood they should not act on feelings & 4 \\
\hline How internship dealt with sexual attraction issues & 7 \\
\hline Sexual attraction addressed didactically & 7 \\
\hline Sexual attraction addressed (or could have been) in supervision & 3 \\
\hline Sexual attraction not addressed & 9 \\
\hline Suggestions for training programs and internships & 5 \\
\hline Include didactic instruction in curriculum & \\
\hline Normalize sexual attraction & \\
\hline Address sexual attraction individually in supervision & \\
\hline Discuss appropriate behaviors & \\
\hline Create a safe environment & \\
\hline Note. Categories that incuded fewer than & cases are not shown \\
\hline
\end{tabular}

Note. Categories that included fewer than 3 cases are not shown.

${ }^{a}$ Only 12 cases had terminated.

\section{Emergence of Sexual Attraction}

The sexual attraction typically emerged after therapy began (e.g., developed over the first third of therapy as the relationship grew closer), whereas it occurred at first sight (e.g., at intake or first session) occasionally.

\section{Therapist Experience of Sexual Attraction}

The feelings associated with the sexual attraction were typically negative (e.g., the therapist felt scared, guilty, and hyperaware when realizing the attraction to the client), but in a few cases the feelings were positive (e.g., the therapist enjoyed being in a therapeutic relationship in which he or she felt well-matched intellectually with 
the client). Therapists typically noted that they experienced a physical response during sessions with the client (e.g., the therapist experienced a visceral physical response to client).

\section{Client Factors Associated With Therapist Sexual Attraction}

Therapists typically reported that their clients were physically attractive (e.g., the therapist noted that client was his or her "type"). Therapists also typically noted interpersonal factors associated with their attraction to the client, which could be divided into four subcategories, the first of which was typical and the last three, variant:

(a) client was a good therapy client (e.g., client was brilliant, articulate, sophisticated, and richer in attributes than other clients), (b) client seemed needy or vulnerable (e.g., therapist saw client as vulnerable because client's fiancée recently broke off their engagement), (c) client was sexually provocative or flirtatious (e.g., client was coy and childlike), and (d) client had an attractive personality (e.g., pensiveness, philosophy of life, intellectualism). As additional variants, therapists noted a similarity between themselves and their clients (e.g., client was similar to therapist in age and minority status, and therapist identified with client's struggles about ways to relate more genuinely with people), therapists mentioned that the client was similar to the therapist's previous or current romantic partner (e.g., the client resembled therapist's wife), and therapists indicated that clients were not the usual type to whom they were attracted.

\section{Client Awareness of Sexual Attraction}

Therapists typically reported that they had no indication that the client was aware of their sexual attraction. For example, one therapist believed that the client's lack of awareness was partially due to the client's not assuming that a same-sex therapist would be sexually attracted to him.

\section{Client Reciprocation of Sexual Attraction}

Instead of a typical pattern in this category, there were three variants: (a) there was no indication that client was sexually attracted to therapist, (b) therapist was uncertain if client was sexually attracted to her or him (e.g., therapist was uncertain about level to which client reciprocated the attraction, although he hoped she was attracted to him), and (c) therapist thought that client was sexually attracted to her or him (e.g., client wanted a relationship with therapist outside of therapy).

\section{Influence of Sexual Attraction on Therapy Process}

Therapists typically believed that they were more invested, caring, and attentive than usual because of the sexual attraction (e.g., the therapist was more psychically invested than in other short-term cases). They also typically believed that the sexual attraction created tension or distance (e.g., therapist was cautious and distanced herself from client to compensate for sexual attraction). Occasionally, therapists reported that the sexual attraction (a) contributed to the therapist's being too giving and losing boundaries with the client (e.g., therapist recognized her tendency to be protective of client), (b) was intrusive and distracting (e.g., therapist was distracted in session by client's physical attributes, which caused therapist to be less attentive to what client was saying), or (c) created less objectivity (e.g., therapist was concerned about attributing insight to the client that client did not have).

\section{Influence of Sexual Attraction on Termination and Outcome}

Twelve of the 13 cases had been terminated at the time of the study. Of these 12 cases, therapists typically had difficulty with termination (e.g., the therapist felt more rejected than typical when client terminated unilaterally), although as a variant, therapists reported no effect on termination. As for outcome, therapists typically believed that there was no effect or they were uncertain of the effects of the sexual attraction on outcome. 
Typically, therapists reported that they had no dreams about the client. However, a few occasionally reported having dreams of a sexual nature, some of which alerted the therapist to the sexual attraction or intensified the sexual attraction. One therapist reported becoming aware of the sexual attraction after the first session when she had a sexual dream about the client. She dreamed of a fire that had not quite reached her house. She was trying to evacuate her family and dog. She opened the door and her client, who was dressed as a firefighter, had come to rescue them. In the dream, she felt relieved and attracted, and she thought of her client as a hero. The therapist interpreted the dream as sexual because the fire connoted sexuality and passion to her. She felt disturbed by the dream because it felt incestuous (she had previously been aware of having a maternal countertransference toward the client), and it suggested a reversal of roles in that the client rescued the therapist and took care of her needs.

Therapists typically reported no fantasies, although a few therapists reported having fantasies of a sexual nature (e.g., a therapist had fantasies of sexual seduction that took place in the therapist's office). Overall, therapists typically reported having either dreams or fantasies but not both.

\section{Management of Sexual Attraction}

Therapists reported that they managed their feelings and thoughts of sexual attraction in five ways. First, therapists typically thought about, reflected on, or worked through the sexual attraction feelings and thoughts on their own (e.g., one participant tried to be honest with herself and aware of her attraction to the client). Second, therapists occasionally discussed the sexual attraction with their supervisors. Third, therapists occasionally became more attentive or cautious with the case (e.g., one therapist was more planful than usual). Fourth, therapists occasionally discussed the sexual attraction with others such as their therapists. Finally, therapists occasionally denied, refocused, or repressed the feelings or thoughts of sexual attraction (e.g., one therapist "shoved" the sexual attraction out of his mind and kept busy).

\section{Resolution of Sexual Attraction}

Therapists typically reported that the sexual attraction was not completely resolved or worked through (e.g., one therapist felt sexual attraction was mostly resolved; one therapist felt that he would still be attracted to the client if he worked with her now). In a few cases, however, the therapists reported that the sexual attraction was completely resolved.

\section{Therapist Factors Concurrent With Sexual Attraction}

Two therapist factors were occasionally reported at the time of the therapist's sexual attraction to the client. First, in terms of relationships, a few therapists were in problematic romantic relationships (e.g., at the time of the work with the client, the therapist was being "strung along" in a relationship, and this made her take the client's side when working with similar relationship issues), a few were in relatively good romantic relationships (e.g., the therapist was involved in a 4-year, committed, monogamous, fulfilling, fun relationship at the time), and a few were not currently involved in romantic relationships. Second, a few therapists reported being under a lot of stress at the time of the sexual attraction (e.g., graduate school was very difficult for the therapist).

\section{Supervision}

Table 2 shows the number of cases for the supervision domain. Seven of the participants disclosed their sexual attraction to their supervisors, and six did not disclose their sexual attraction to their supervisors. Results are described separately for these two groups. For each of the two subgroups, we considered the category to be general if it applied to all of the cases, typical if it referred to at least half of the cases, and variant it referred to at least two but less than half of the cases. 
Table 2. Number of Cases for the Supervision Domain and Categories From the Cross-Analysis of the 13 Cases of Sexual Attraction

\begin{tabular}{|l|l|}
\hline Domain and category & No. of cases \\
\hline Disclosed to supervisor & \\
\hline Who initiated discussion of sexual attraction & 5 \\
\hline Trainee & 2 \\
\hline Supervisor & \\
\hline Supervisor response & 7 \\
\hline Helpful & 7 \\
\hline Sexual attraction normalized, validated, and supported & 6 \\
\hline Enabled trainee ot explore and cope with sexual attraction & 3 \\
\hline Not helpful/not enough discussion/probed too much & \\
\hline Relationship with supervisor & 7 \\
\hline Positive aspects & 3 \\
\hline Negative aspects & 6 \\
\hline Disclosure of sexual attraction strengthened supervisory relationship & \\
\hline Not disclosed to supervisor & \\
\hline Reasons for nondisclosure & 4 \\
\hline Negative feelings about supervisor/would not be supportive & 3 \\
\hline Sexual attraction not significant enough/not relevant & \\
\hline Relationship with supervisor & 4 \\
\hline Positive aspect & 4 \\
\hline Negative aspect & 4 \\
\hline Nondisclosure of sexual attraction weakened supervisory relationship & 5 \\
\hline Beneficial discussion with others (peers, family members, therapist) & 5 \\
\hline Note. For the supervision doman, the totalnumber of cases possible was \\
\hline
\end{tabular}

Note. For the supervision domain, the total number of cases possible was 7 for the disclosure group and 6 for the nondisclosure group. Categories that included fewer than 2 cases are not shown.

\section{Disclosed to supervisor}

For those who disclosed, the disclosure was typically initiated by the trainee. In terms of the supervisor's response, all trainees reported that the supervisor was helpful by normalizing, validating, and supporting. Trainees also typically reported that supervisors enabled them to explore and cope with the sexual attraction. In one case, the trainee stated that the supervisor helped monitor the sexual attraction and provided objective feedback about it. In another example, the trainee mentioned that the supervisor asked in a nonintrusive fashion about personal issues that might have fostered the sexual attraction. However, trainees occasionally reported that some of the supervisors' responses were not helpful because the sexual attraction was not discussed enough or the supervisor probed too much (e.g., the therapist did not find it helpful when the supervisor tried to process physical attraction that the therapist did not feel was there).

In terms of the supervisory relationship, positive aspects emerged for all cases in the disclosure group (e.g., excellent relationship, relationship was honest, supportive, and good). A few therapists also reported negative aspects (e.g., supervisor discussed tangential topics, supervisory relationship was initially difficult). Finally, therapists typically reported that discussing the sexual attraction strengthened the supervisory relationship. One therapist mentioned that the discussion of the sexual attraction confirmed a good relationship, and another believed that the sexual attraction issue brought the therapist closer to the supervisor. 
Not disclosed to supervisor

Typically, those therapists who did not disclose to their supervisors their feelings of sexual attraction reported negative feelings about the supervisor or concern that the supervisor would not be supportive. One therapist believed that the supervisor was not competent enough, and another mentioned that the supervisor was insensitive and disrespectful toward her. Another reason for not disclosing to supervisors was that the sexual attraction was not considered significant enough or relevant to supervision (e.g., the therapist thought attraction was more appropriate to talk about with her therapist and her friends in a peer supervision group).

In terms of the supervisory relationship, therapists typically mentioned positive and negative aspects. Examples of positive aspects included statements that the supervisor was supportive or complimentary. Negative aspects included statements that the supervisor was distant and competitive or sexually harassed the therapist. The sexual attraction issue typically had a negative effect on the supervisory relationship. One trainee reported that not discussing the sexual attraction added distance to an already distant supervisory experience. Relatedly, therapists who did not disclose their sexual attraction to their supervisors typically found it beneficial to discuss the sexual attraction with others, including peers, family members, and their therapists.

\section{How Training Program Dealt With Sexual Attraction Issues}

Table 1 shows that therapists typically reported that sexual attraction was not addressed adequately in their training programs. For example, one therapist stated that sexual attraction was only mentioned by some faculty in practica, and another stated that there was minimal exposure in the training program to the topic of sexual attraction. Therapists also typically reported that they were instructed to talk to their supervisors, seek consultation, refer the client elsewhere, or obtain therapy when they felt sexually attracted to their clients. In addition, therapists typically stated that sexual attraction issues were addressed in ethics classes. A few therapists, however, reported that the training programs were not open or safe environments in which to discuss sexual attraction (e.g., one therapist stated that students were hesitant to discuss sexual attraction because it could be dangerous professionally to do so).

\section{How Internship Dealt With Sexual Attraction Issues}

Table 1 also shows that sexual attraction was typically addressed didactically in internships (e.g., interns were given a book on the topic, or sexual attraction was discussed in the context of a seminar). Therapists typically reported that they knew they could talk to their supervisors, suggesting that sexual attraction was addressed informally. In a few cases, sexual attraction toward clients was not addressed in any manner.

\section{Suggestions for Training Programs and Internships}

Therapists typically suggested that training programs and internships include didactic instruction in the curriculum (e.g., discuss case examples and use videotape training to educate students). Also, participants typically felt a need for sexual attraction to be normalized by training programs and internships. Other suggestions by a few therapists included addressing sexual attraction individually in supervision, discussing appropriate behaviors (e.g., emphasizing not to act on the feelings in therapy), and creating a safe environment (e.g., discussing sexual attraction in a safe setting where students can explore their feelings and talk openly; see Table 1).

\section{Narrative Example of a Therapist's Experience of Sexual Attraction}

The intern, "Martin," was a White man in his early 30s who used both cognitive-behavioral and humanistic theory in his work. The client was a 21-year-old White woman who sought therapy for depression and substance 
abuse. The supervisor was a White man in his 30 s who was psychodynamically oriented. Martin met with his client once a week for about 6 months before ending treatment with her about 1 week before being interviewed for the study.

At the time of therapy, Martin was dating, but he was not in a serious, long-term relationship. He noticed that he was sexually attracted to his client in about the second session, when he experienced an emotional and physical response to her presence. The client was not only physically attractive to Martin but also impressed him as articulate, sophisticated, and generally richer in interpersonal attributes than other clients. Martin had never been sexually attracted to a client before and was very distressed by the situation; he experienced a range of negative feelings. For example, he felt embarrassed that he was sexually attracted to someone who had numerous complex problems. He felt guilty that he was devoting more attention to this client than to others, and he felt "tortured" inside because he enjoyed being attracted to her and did not try to change his feelings. In fact, as the sessions progressed, Martin found himself looking forward to seeing the client each week. Thus, the sexual attraction created an emotional dilemma that he struggled to manage.

Although his training program and internship neglected the discussion of sexual attraction to clients, Martin understood that the proper procedure in such cases was to address the issue in supervision. Unfortunately, he felt he could not discuss his predicament with his current supervisor for several reasons. For instance, he felt that discussing sexual issues with this supervisor was off limits because of related issues Martin was aware of in the supervisor's life. Also, because this was a high-risk case that Martin wanted to keep, he feared that if he disclosed in supervision that he was sexually attracted to the client, his supervisor would ask him to give up the case. Despite these concerns, Martin said that he would have talked about the sexual attraction if the supervisor had broached the topic, but the supervisor never did. Martin suspected that the supervisor might have sensed the presence of the sexual attraction but did not bring it up out of respect for Martin's privacy.

Martin speculated that the main benefit of discussing the situation in supervision would have been to reduce his turmoil rather than to change how he was working with the client. Indeed, he believed that because the sexual attraction forced him to stay focused on the client's issues, the client received better care than Martin's other clients. Despite not addressing the situation in supervision, his experience was normalized to some degree when he discussed his sexual attraction to the client with a fellow intern who had a similar experience. Martin's additional strategy for managing the sexual attraction was to read Pope et al.'s (1993) book on sexual feelings in therapy and to be mindful of not harming the client. Thus, although his feelings for the client never changed, he believed the sexual attraction did not have a detrimental effect on the client.

Nevertheless, Martin noticed a blurring of his professional boundaries in this situation, as evidenced by his eager anticipation of sessions with this client. He also realized that his sexual attraction to her created distance between them as he struggled to compensate for his feelings. For example, although it was not his usual style to avoid physical contact with clients, he became cautious about avoiding casual touch with this client.

According to Martin, the termination did not go well in this case. The client had to leave therapy on short notice because she had to move away from the area unexpectedly, and this, in addition to Martin's strong feelings for her, made it difficult for him to prepare for termination as he normally would. In fact, when he ended treatment with this client, he regretted not having addressed issues that he typically would have covered when terminating with other clients. Although Martin was not sure if the client was attracted to him, he believed that neither of them was ready to end the relationship. Martin's feelings for the client ended when she left, but he was uncertain if the issue of being sexually attracted to her was resolved.

\section{Discussion}

The results of this study indicate that interns report feeling sexual attraction toward their clients, and there appears to be consistent patterns in their experiences of sexual attraction. The development of sexual attraction 
toward clients typically occurred in the beginning stages of therapy, which coincides with the therapeutic phase in which the working alliance is rapidly maturing (Bordin, 1979; Gelso \& Carter, 1985). Perhaps the emotional intensity of a developing relationship, combined with physically and interpersonally attractive client qualities, facilitated the development of sexual attraction to clients. Given this scenario, it is not surprising that most therapists will at some point in their practice become sexually attracted toward a client. Relatedly, the beginning phase of therapy has also been found to be when sexual contact with clients often occurs (Bouhoutsos, Holroyd, Lerman, Forer, \& Greenberg, 1983).

Although some therapists found the sexual attraction exciting, most noted negative feelings of guilt and fear, which was consistent with previous research examining the sexual attraction process (e.g., Pope et al., 1986; Rodolfa et al., 1994). Although the physical and some of the interpersonal aspects of a therapist's attraction to a client appear to be common to relationships in general, some of the interpersonal aspects were clearly specific to therapy (e.g., client was a good therapy client and client seemed needy or vulnerable). Furthermore, the interpersonal aspects, such as the client's neediness and flirtatiousness, may be diagnostic of key therapeutic issues for therapists and clients (e.g., a therapist or a client may tend to sexualize relationships; Brodsky, 1985). Ultimately, additional research that investigates how these interpersonal aspects are related to therapeutic process and outcome is necessary.

Almost all of the therapists perceived no indication that the client was aware of the therapist's sexual attraction. This finding presumes that the therapist was able to hide the sexual attraction or that the client was not insightful enough to recognize the sexual attraction. Given that these ideas stem from the therapist's perception, it would be fruitful to explore clients' reactions and perceptions to determine whether clients are in agreement with therapists (Hill, Thompson, Cogar, \& Denman, 1993). Furthermore, none of the therapists disclosed their sexual feelings to their clients, which may be appropriate given that the treatment efficacy of such disclosures is uncertain (Goodyear \& Shumate, 1996; Pope et al., 1993).

Most of the therapists believed that their clients were not sexually attracted to them, indicating that the sexual attraction was predominately in one direction. However, it might be expected that the sexual attraction was reciprocal because of the mutuality of the therapeutic experience. It is important for future researchers to assess the client's perspective to determine the extent to which the therapist's perception is indeed accurate. Trainees' typical beliefs and their reactions to having someone attracted to them or the manner in which their sexual attraction to others is usually manifested may prove fruitful to explore as potential interventions in supervision. In this way, supervisors could determine the extent to which the sexual attraction is indeed unidirectional.

According to the therapists, their sexual attraction appeared to have an effect on the therapy process. Consistent with the survey findings (Bernsen et al., 1994; Pope et al., 1986; Rodolfa et al., 1994), most therapists perceived that the sexual attraction led to both beneficial and negative therapeutic effects. Therapists reported becoming more invested and caring about the clients to whom they were sexually attracted while recognizing that the sexual attraction contributed to their overinvestment (i.e., their becoming too giving and their losing touch with their emotional boundaries). Ultimately, without clients' reports or objective observations, it is unclear whether a therapist's overinvestment is actually beneficial or harmful to therapy.

Most therapists reported either dreams or fantasies of a sexual nature about their clients. These dreams or fantasies sometimes alerted therapists to the sexual attraction and related problems. These results suggest that therapists should pay attention to their dreams and fantasies for clues about their feelings toward clients. In addition, supervisors should be alert to therapists' dreams and fantasies about clients and their relevance to discussion in supervision. 
More than half of the therapists believed that their sexual attraction was not resolved and that some residual feelings of sexual attraction remained at the end of treatment. Research is needed to investigate how to help trainees resolve their feelings appropriately and effectively. Moreover, what constitutes resolution of sexual attraction needs to be clarified. Specifically, resolution need not imply that therapists no longer have thoughts or feelings about their sexual attraction to clients. Perhaps resolution consists of greater understanding and insight into the feelings of sexual attraction rather than of a complete absence of thoughts and feelings of this nature (Bridges, 1994).

The results regarding therapist factors provided a mixed picture of the status of therapists' relationships and of concurrent stressors and therefore must be interpreted with caution. It seemed that there was an equal mix of therapists in good and in problematic romantic relationships. Furthermore, only some of the therapists reported concurrent stressors. It is unclear if the relationship statuses and stressors described here are characteristic of most predoctoral interns or are unique to therapists who are sexually attracted to their clients. Thus, although linking relationship status or concurrent stressors to sexual attraction is intuitively appealing, the results do not support this notion.

\section{Supervision}

About half of the participants disclosed to a supervisor their feelings of sexual attraction. Thus, trainees in this study who had direct access to supervisors did not use supervision as a resource for dealing with issues of sexual attraction any more frequently than did postdegree therapists (Rodolfa et al., 1994). The findings indicated that the trainees were the ones who typically initiated the discussion about the sexual attraction. In fact, out of the 13 cases of sexual attraction, only two supervisors initiated the discussion of issues of sexual attraction. In one of the nondisclosure cases, the trainee told her supervisor that the client was the most sensual person she had ever met, yet the supervisor did not investigate this further. Perhaps supervisors did not initiate discussion of sexual attraction because of their own discomfort with the topic or because the trainees avoided mentioning their sexual attraction. As has been found in previous research, trainees seemed adept at not disclosing what they did not want their supervisors to know, especially when they had a negative supervisory relationship (Ladany et al., 1996). When the supervisor initiated a discussion of the sexual attraction, the trainees felt relieved and welcomed the opportunity to process the issue. These results suggest that it might be helpful for supervisors to attend more closely to sexual attraction issues and to initiate exploration of these issues in a gentle and supportive manner.

Overall, trainees found it particularly helpful when supervisors normalized and validated their experiences and enabled them to explore feelings. Thus, for some trainees, supervision became a primary place in which to work on their issues of sexual attraction. The effectiveness of the supervisory intervention seemed to stem from a blend of supervisory approaches involving both didactic (e.g., normalization) and counseling (e.g., exploration) styles. These approaches highlight the importance of supervisory styles involving flexibility, understanding, and comprehensiveness to meet the needs of trainees.

The supervisory relationship seemed to be a key factor in the decision for trainees to disclose their sexual attraction issues to supervisors. Specifically, trainees were more likely to make disclosures about sexual attraction when the supervisory relationship was mostly positive and supportive than when it had relatively equal amounts of positive and negative aspects. Several trainees who did not disclose their sexual attraction toward a client thought that their supervisor would not be helpful or supportive. As in therapy, the supervisory working alliance may be a very important factor in determining trainee-and ultimately client-outcome (Bordin, 1983; Efstation, Patton, \& Kardash, 1990; Ladany \& Friedlander, 1995; Patton \& Kivlighan, 1997). Not surprisingly, disclosure to a supervisor strengthened an already positive relationship, whereas nondisclosure weakened an already weak relationship. 
The results also demonstrate that whether or not they disclosed to a supervisor, trainees were very likely to reveal and discuss sexual attraction issues with peers and therapists. They found these discussions beneficial for the same reasons as did those who discussed the sexual attraction issue with their supervisors (i.e., normalization and support). Thus, when they believed their supervisors would not be helpful, some trainees were able to approach others to satisfy their need for supervision on these issues. As in Ladany et al.'s $\underline{(1996)}$ study, it appears that peer supervisors provide a great deal of supervision.

On the basis of the results of this study, we have several suggestions for supervision. Given that previous research suggests that disclosure of sexual attraction in supervision facilitates positive outcome in therapy, we suggest that supervisors (a) be alert to the possibility among trainees of their sexual attraction to clients (Ellis \& Douce, 1994), (b) foster a supervisory relationship that is mutually warm, understanding, and trusting, (c) initiate discussions regarding sexual attraction in the context of a positive and open supervisory relationship, (d) be flexible in their approach to supervision, and (e) process sexual attraction issues extensively when trainees ask (or hint) for assistance. Furthermore, assessing and assisting trainees with their sexual feelings toward clients seem to be relevant focal points in the training of clinical supervisors.

\section{Training}

Overall, the majority of the participants believed that sexual attraction to clients was not addressed adequately in their training programs and was addressed somewhat during their internships. Perhaps psychotherapy educators may not believe that beginning trainees are ready to handle advanced skills such as examining sexual feelings in therapy and working through countertransference issues. However, this developmental stance may be without merit (e.g., Ellis \& Ladany, 1997; Holloway, 1987); further study is warranted to determine the extent to which beginning and advanced trainees can manage and understand issues of therapist sexual attraction to clients. In terms of internships, it appears that in some cases an attempt was made to provide didactic information, but the information may have been inadequate. Thus, it seems important that professors and internship supervisors approach therapist sexual attraction in a more comprehensive fashion than currently exists (Ellis \& Douce, 1994; Rodolfa, Kitzrow, Vohra, \& Wilson, 1990; Vasquez, 1988). The interns suggested that beyond normalizing sexual attraction, training programs and internships should address sexual attraction issues in practica to provide students with knowledge about how to manage sexual attraction to clients. The trainees also felt it would be beneficial if the instruction on sexual attraction was not solely didactic but also included experiential components as well as examples of how senior therapists or faculty dealt with sexual attraction in their work with clients. Furthermore, according to trainees, this discussion should be conducted in a safe and open environment so that the topic of sexuality can be broached and students' sexual feelings can be explored.

\section{Limitations}

One limitation of this study is the generalizability from a small sample. At best, only tentative hypotheses can be generalized to psychology interns. In addition, postdoctoral therapists (who may be able to choose their supervisors) or beginning practicum therapists (who may also be contending with other developmental issues; Stoltenberg \& Delworth, 1987) may not experience similar processes with regard to sexual attraction to clients. A second limitation pertains to participant self-selection and response rate. Although the return rate for this study was consistent with other qualitative studies (e.g., Rhodes, Hill, Thompson, \& Elliott, 1994), we do not know whether those therapists who did not participate would have reported different reactions. For example, it is unknown if those who did not participate were more or less likely to have been sexually attracted to, or involved with, a client than those who participated. Third, although we attempted to address the influence of researcher bias on the data analysis, it is possible that some of the findings are unique to the manner in which we as a group interpreted the data. Furthermore, some uniqueness can be attributed to the manner in which the interview questions were originally formulated, as well as addressed, in the interview. Thus, replications and 
extensions with other subsamples of participants and with other researchers to code the data as well as to formulate and direct the interview questions are warranted.

\section{Directions for Future Research}

We suggest that investigators attend more closely to the manner in which therapists' sexual attraction to clients influences the process and outcome of therapy. Also, it is important to determine the extent to which client factors, therapist factors, and client-therapist interactions contribute to the development of therapists' sexual attraction. In addition, the manner in which sexual attraction in therapy has been assessed should be expanded. A full understanding of the sexual attraction process and how it might influence therapy process and outcome involves identifying clients' reactions and attraction to the therapist (i.e., not only therapists' perceptions) as well as making behavioral observations of the therapeutic interactions.

Another potential area of investigation is to determine the manner in which parallel process issues are occurring in the therapy and supervisory relationships (Alpher, 1991; Ekstein \& Wallerstein, 1972; Friedlander, Siegel, \& Brenock, 1989; Pope, Schover, \& Levenson, 1980). Specifically, it seems salient to examine the extent to which sexual issues are manifested in both the therapy relationship and the supervisory relationship. A further area of study is the extent to which the supervisory relationship influences the likelihood of therapist disclosure in supervision. In particular, examining the relation between the supervisory working alliance and trainee selfdisclosure of sexual attraction to a client might prove worthwhile. Furthermore, delineating the salient features of sexual attraction that lead to sexual contact (Bates \& Brodsky, 1989) is important. Moreover, it is necessary to determine the extent to which supervisors are able to identify and provide adequate interventions for trainees who are sexually attracted to their clients (e.g., what do supervisors look for and how do they decide to broach the topic?). Finally, investigating the most effective methods of training therapists and supervisors to manage and resolve therapists' feelings of sexual attraction toward their clients is relevant to psychotherapy training programs.

\section{References}

Alpher, V. S. (1991). Interdependence and parallel processes: A case study of structural analysis of social behavior in supervision and short-term dynamic psychotherapy. Psychotherapy, 28, 218-231.

Bates, C., \& Brodsky, A. (1989). Sex in the therapy hour: A professional case of incest. New York: Guilford Press. Bernard, J. M., \& Goodyear, R. (1992). Fundamentals of clinical supervision. Carmelle, IN: Allyn \& Bacon.

Bernsen, A., Tabachnick, B. G., \& Pope, K. S. (1994). National survey of social workers' sexual attraction to their clients: Results, implications, and comparison to psychologists. Ethics \& Behavior, 4, 369-388.

Blocher, D. H. (1983). Toward a cognitive developmental approach to counseling supervision. The Counseling Psychologist, 11, 27-34.

Bordin, E. S. (1979). The generalizability of the psychoanalytic concept of the working alliance. Psychotherapy: Theory, Research, and Practice, 16, 252-260.

Bordin, E. S. (1983). A working alliance based model of supervision. The Counseling Psychologist, 11, 35-42.

Bouhoutsos, J. C., Holroyd, J., Lerman, H., Forer, B., \& Greenberg, M. (1983). Sexual intimacy between psychologists and patients. Professional Psychology: Research and Practice, 14, 185-196.

Bridges, N. A. (1994). Meaning and management of attraction: Neglected areas of psychotherapy training and practice. Psychotherapy, 31, 424-433.

Brodsky, A. M. (1985). Sex between therapists and patients: Ethical gray areas. Psychotherapy in Private Practice, 3, 57-62.

Efstation, J. F., Patton, M. J., \& Kardash, C. M. (1990). Measuring the working alliance in counselor supervision. Journal of Counseling Psychology, 37, 322-329.

Ekstein, R., \& Wallerstein, R. S. (1972). The teaching and learning of psychotherapy (2nd ed.). New York: Basic Books. 
Ellis, M. V., \& Douce, L. A. (1994). Group supervision of novice clinical supervisors: Eight recurring issues. Journal of Counseling and Development, 72, 520-525.

Ellis, M. V., \& Ladany, N. (1997). Inferences concerning supervisees and clients in clinical supervision: An integrative review. In C. E.Watkins, Jr. (Ed.), Handbook ofpsychotherapy supervision (pp. 447-507). New York: Wiley.

Freud, S. (1983). Further recommendations in the technique of psychoanalysis: Observations on transferencelove. In P.Reiff (Ed.), Freud: Therapy andtechnique (pp. 167-180). New York: Collier Books. (Original work published 1915).

Friedlander, M. L., Siegel, S. M., \& Brenock, K. (1989). Parallel process in counseling and supervision: A case study. Journal of Counseling Psychology, 36, 149-157.

Gabbard, G. O. (1994). Sexual excitement and countertransference love in the analyst. Journal of the American Psychoanalytic Association, 42, 1083-1106.

Gabbard, G. O. (1995). The early history of boundary violations in psychoanalysis. Journal of the American Psychoanalytic Association, 43, 1115-1136.

Gelso, C. J., \& Carter, J. A. (1985). The relationship in counseling \& psychotherapy: Components, consequences, and theoretical antecedents. The Counseling Psychologist, 13, 155-243.

Goodyear, R. K., \& Shumate, J. L. (1996). Perceived effects of therapist self-disclosure of attraction to clients. Professional Psychology: Research and Practice, 27, 613-616.

Hill, C. E., Thompson, B. J., Cogar, M. C., \& Denman, D. W. (1993). Beneath the surface of long-term therapy: Therapist and client report of their own and each other's covert processes. Journal of Counseling Psychology, 40, 278-287.

Hill, C. E., Thompson, B. J., \& Williams, E. N. (in press). A guide to conducting consensual qualitative research. The Counseling Psychologist.

Holloway, E. L. (1987). Developmental models of supervision: Is it supervision?Professional Psychology: Research and Practice, 18, 209-216.

Kaplan, H. S. (1977). Training of sex therapists. In W. H.Masters, V. E.Johnson, \& R. D.Kolodny (Eds.), Ethical issues in sex therapy and research (pp. 182-189). Boston: Little, Brown.

Ladany, N., \& Friedlander, M. L. (1995). The relationship between the supervisory working alliance and supervisee role conflict and role ambiguity. Counselor Education and Supervision, 34, 220-231.

Ladany, N., Hill, C. E., Corbett, M. M., \& Nutt, E. A. (1996). Nature, extent, and importance of what psychotherapy trainees do not disclose to their supervisors. Journal of Counseling Psychology, 43, 1024.

McCracken, G. D. (1988). The long interview. Newbury Park, CA: Sage.

Nickell, N. J., Hecker, L. L., Ray, R. E., \& Bercik, J. (1995). Marriage and family therapists' sexual attraction to clients: An exploratory study. American Journal of Family Therapy, 23, 315-327.

Patton, M. J., \& Kivlighan, D. M., Jr. (1997). Relevance of the supervisory alliance to the counseling alliance and to treatment adherence in counselor training. Journal of Counseling Psychology, 44, 108-115.

Pope, K. S. (1990). Therapist-patient sexual involvement: A review of the research. Clinical Psychology Review, 10, 477-490.

Pope, K. S., Keith-Spiegel, P., \& Tabachnick, B. (1986). Sexual attraction to clients: The human therapist and the (sometimes) inhuman training system. American Psychologist, 41, 147-158.

Pope, K. S., Schover, L. R., \& Levenson, H. (1980). Sexual behavior between clinical supervisors and trainees: Implications for professional standards. Professional Psychology, 10, 157-162.

Pope, K. S., Sonne, J. L., \& Holroyd, J. (1993). Sexual feelings in psychotherapy: Explorations for therapists and therapists-in-training. Washington, DC: American Psychological Association.

Pope, K. S., \& Tabachnick, B. G. (1993). Therapist anger, hate, fear, and sexual feelings: National survey of therapist responses, client characteristics, critical events, formal complaints, and training. Professional Psychology: Research and Practice, 24, 142-152.

Rhodes, R. H., Hill, C. E., Thompson, B. J., \& Elliott, R. (1994). Client retrospective recall of resolved and unresolved misunderstanding events. Journal of Counseling Psychology, 41, 473-483. 
Rodolfa, E., Hall, T., Holms, V., Davena, A., Komatz, D., Antunez, M., \& Hall, A. (1994). The management of sexual feelings in therapy. Professional Psychology: Research and Practice, 25, 168-172.

Rodolfa, E. R., Kitzrow, M., Vohra, S., \& Wilson, B. (1990). Training interns to respond to sexual dilemmas. Professional Psychology: Research and Practice, 21, 313-315.

Stake, J., \& Oliver, J. (1991). Sexual contact and touching between therapists and clients: A survey of psychologists' attitudes and behavior. Professional Psychology: Research and Practice, 22, 297-307.

Stoltenberg, C. D., \& Delworth, U. (1987). Supervising counselors and therapists: A developmental perspective. San Francisco: Jossey-Bass.

Vasquez, M. J. T. (1988). Counselor-client sexual contact: Implications for ethics training. Journal of Counseling and Development, 67, 238-241.

Yarris, E., \& Allgeier, E. R. (1988). Sexual socialization for therapists: Applications for the counseling/psychotherapy of women. Women \& Therapy, 7, 57-75.

Submitted: February 24, 1997 Revised: June 2, 1997 Accepted: June 4, 1997 